\title{
Prediksi Jejak Karbon Fakultas Sains dan Teknologi Kampus Pinang Masak Universitas Jambi
}

\author{
Nurhayat $^{1}$, Rizki Andre Handika ${ }^{1 *}$ \\ ${ }^{1}$ Program Studi Teknik Lingkungan, Fakultas Teknik, Universitas Jambi \\ Jln. Tribrata Km. 11 Pondok Meja, Kec. Mestong, Kabupaten Muaro Jambi 36364 \\ *e-mail: rizki_ah@unja.ac.id
}

\begin{abstract}
The existence of Universities that include many human activities for energy consumption such as electrical and fossil fuel energy would be affected to $\mathrm{CO}_{2}$ emission. As the most important component of greenhouse gases $(\mathrm{GHG}), \mathrm{CO}_{2}$ will induce global warming, which become climate change condition. This research was intended to predict the amount of $\mathrm{CO}_{2}$ emission from campus activities using International Panel Climate Change (IPCC) method. Location for the research sample was in Faculty of Science and Technology (FST), Pinang Masak Campus of Jambi University, which the carbon emission sources were identified to three scope based on The Greenhouse Gas Protocol. Carbon footprint scope 1 comprises from operational vehicle activities and use of LPG in Canteen in aggregate 12,18 ton. $\mathrm{CO}_{2}$-eq. However, scope 2 comes from the use of electrical which amount to 100,29 ton.CO $\mathrm{CO}_{2}$-eq and scope 3 which consist of transportation activities and the use of paper by FST lecturers, staff and students with amount 443,64 ton. $\mathrm{CO}_{2}$-eq. Therefore, the total amount of carbon footprint in FST Campus was 556,10 ton. $\mathrm{CO}_{2}$-eq.
\end{abstract}

Keywords: Campus activity; $\mathrm{CO}_{2}$ emission; Carbon footprint; Climate change.

\section{Pendahuluan}

Salah satu tantangan serius yang dihadapi di abad 21 ini adalah perubahan iklim (Wulandari, 2013). Perubahan iklim merupakan salah satu dampak dari pemanasan global yang telah menjadi isu internasional dan terus menjadi sorotan di berbagai macam kalangan. Penyebab utamanya bersumber dari gas rumah kaca (GRK) yang menyebabkan terjadinya efek rumah kaca di permukaan bumi.

Peningkatan emisi gas rumah kaca (GRK) merupakan masalah serius, dimana emisi gas karbondioksida $\left(\mathrm{CO}_{2}\right)$ merupakan komponen utama gas rumah kaca. Peningkatan gas $\mathrm{CO}_{2}$ secara signifikan bersumber dari emisi antropogenik terutama dari sektor energi: pemanfaatan bahan bakar fosil seperti batubara, minyak bumi, dan gas alam (Alwin, 2016). Pembangkit listrik, penggunaan peralatan elektronik, penggunaan kendaraan bermotor dan aktivitas industri merupakan segelintir contoh kegiatan manusia yang turut memperbesar emisi gas rumah kaca. Kondisi ini diperparah lagi dengan kasus kebakaran hutan dan lahan yang terus meningkat dan eksploitasi hutan seperti penebangan liar yang mengakibatkan pohon-pohon yang berfungsi menyerap gas karbondioksida $\left(\mathrm{CO}_{2}\right)$ dan menyimpan cadangan karbon menjadi berkurang.

Keberadaan universitas memiliki dampak terhadap lingkungan yang diakibatkan dari aktivitas sehari-hari di universitas. Berbagai kegiatan terjadi di dalam kampus menghasilkan emisi gas karbondioksida $\left(\mathrm{CO}_{2}\right)$ yang berdampak langsung maupun tidak langsung bagi lingkungan yang menyebabkan pemanasan global (Wiedmann \& Minx, 2008). Kegiatan kampus adalah kegiatan perkuliahan dan pemakaian laboratorium, administrasi kampus, dan kegiatan lainnya yang membutuhkan energi. Besarnya aktivitas dan kegiatan yang dilakukan di lingkungan kampus tentu akan berpengaruh terhadap besar emisi $\mathrm{CO}_{2}$ yang dihasilkan.
Penelitian jejak karbon dari kegiatan universitas sudah dilakukan di luar negeri maupun di Indonesia (Sagala, 2016). Universitas Jambi sebagai universitas yang terus berupaya menjadi kampus yang berwawasan lingkungan, maka studi jejak karbon di Universitas Jambi juga perlu dilakukan. Universitas Jambi, sebagai universitas negeri terbesar yang berada di Provinsi Jambi khususnya di Kampus Pinang Masak sebagai Kampus pusat dengan 10 fakultas memiliki bangunan fakultas dan administrasi yang didalamnya terdapat berbagai aktivitas yang tentunya menghasilkan emisi gas $\mathrm{CO}_{2}$. Namun sejauh ini belum diketahui seberapa besar jumlah emisi $\mathrm{CO}_{2}$ di Kampus Pinang Masak Universitas Jambi.

Fakultas Sains dan Teknologi (FST) dipilih sebagai lokasi penelitian karena salah satu fakultas dengan program studi yang cukup banyak dan dengan aktivitas perkuliahan, laboratorium, serta transportasi yang sekiranya dapat mewakilkan aktivitas di Kampus Pinang Masak Universitas Jambi. Fakultas Sains dan Teknologi (FST) Unja memiliki 11 Program Studi dengan jumlah populasi 1.763 Jiwa. Penelitian ini dilakukan untuk mengetahui kontribusi aktivitas kampus terhadap emisi gas $\mathrm{CO}_{2}$ yang dihasilkan.

\section{Metodologi}

\subsection{Lokasi dan Sampel Pengumpulan Data a. Lokasi}

Kampus sebagai sebuah ekosistem yang didalamnya berlangsung berbagai aktivitas akademik menjadi salah satu sumber yang semakin potensial dalam isu jejak karbon. Pertambahan jumlah program studi dan sekaligus juga dengan tingkat strata pendidikannya berdampak langsung terhadap semakin meningkatnya populasi yang beraktivitas di sebuah kampus. Hal tersebut seperti juga terjadi di Universitas Jambi yang pada tahun 2013 baru memiliki 18.793 mahasiswa, pada tahun 2017 tercatat sebanyak 23.181 mahasiswa.

Universitas jambi berdiri sejak 1 April 1963 yang 
awalnya bernama Universitas Negeri Jambi dan baru terdiri dari empat Fakultas yaitu Fakultas Ekonomi, Fakultas Hukum, Fakultas Pertanian, dan Fakultas Peternakan. Seiring waktu selain empat fakultas tadi, dilakukan penambahan lagi dengan Fakultas Keguruan dan Ilmu Pendidikan, Fakultas Kedokteran dan Ilmu Kesehatan, Fakultas Sains dan Teknologi, Fakultas Teknologi Pertanian, Fakultas Ilmu Budaya, Fakultas Ilmu Sosial dan Politik, Fakultas Kehutanan, Fakultas Teknik, dan Fakultas Keolahragaan, sehingga sampai saat ini telah memiliki 13 Fakultas dan 1 Sekolah PascaSarjana.

Dalam penelitian terhadap isu jejak karbon di Universitas Jambi ini dipilih Fakultas Sains dan Teknologi (FST) di Kampus Pinang Masak Universitas Jambi (Unja) sebagai lokus. Fakultas Sains dan Teknologi dipilih karena merupakan salah satu fakultas dengan program studi terbanyak yang dimiliki oleh Universitas Jambi, yaitu terdiri dari 11 program studi. Selain itu kegiatannya pun cukup heterogen, dimana selain perkuliahan dan administrasi akademik, mencakup juga aktivitas di laboratorium serta transportasi, sehingga dianggap dapat mewakili secara umum aktivitas seharihari yang ada di Kampus Pinang Masak Universitas Jambi. Gambaran tentang lokasi penelitian dapat dilihat pada gambar sebagai berikut.

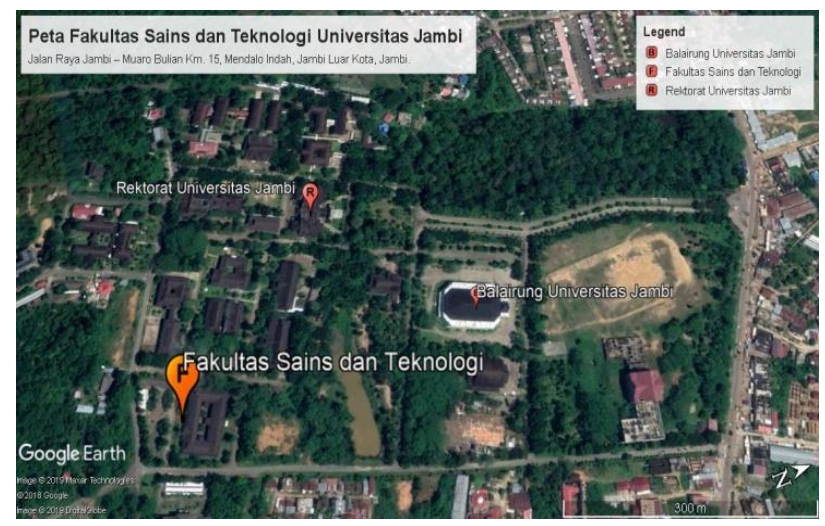

Gambar 1. Kampus Fakultas Sains dan Teknologi Universitas Jambi (Google earth yang telah dimodifikasi, 2019

Kampus Fakultas Sains dan Teknologi terletak di kawasan Unja Mendalo yaitu di Jalan Raya Jambi - Muaro Bulian Km. 15, Mendalo Indah, Jambi Luar Kota, Jambi. Adapun gambaran kondisi gedung perkuliahan dan laboratorium di FST ditampilkan sebagai berikut.

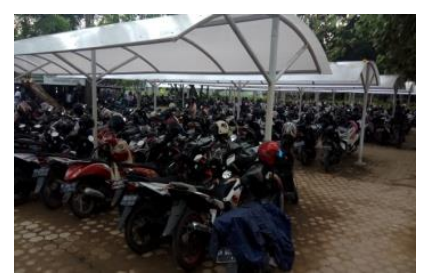

(a)

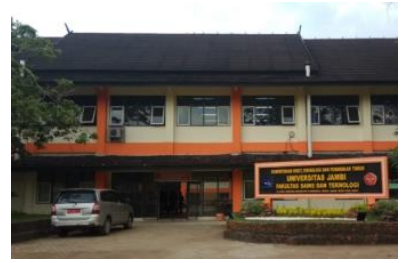

(b)

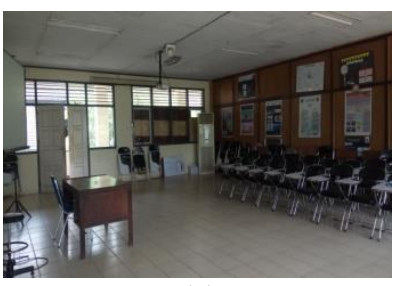

(c)

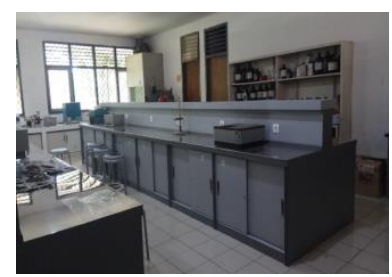

(d)

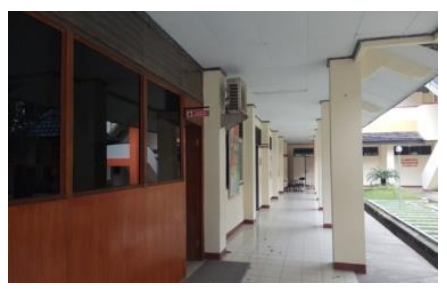

(e)

Gambar 2. (a) Kondisi pelataran parkir; (b) Gedung kampus; (c) Ruang kelas; (d) Ruang laboratorium; dan (e) Kantor administrasi fakultas sains dan teknologi universitas jambi

\section{b. Populasi dan Sampel}

Penelitian ini dilakukan untuk mengkaji jejak karbon aktivitas kampus di lokasi penelitian yaitu di Fakultas Sains dan Teknologi Kampus Pinang Masak Universitas Jambi sebagai objek penelitian. Tidak keseluruhan populasi akan digunakan melainkan hanya sejumlah tertentu berupa sampel. Dari populasi yang ada di lokasi, sampel dipilih menggunakan metode penarikan sampel acak berstrata menggunakan persamaan Slovin berikut ini (Astari, 2012):

$n=N /\left(1+N \alpha^{2}\right)$

Keterangan:

$\mathrm{n} \quad=$ Jumlah sampel wilayah studi (orang)

$\mathrm{N}$ = Jumlah populasi yang berada di area studi (orang)

$\propto \quad=$ Derajat kesalahan

Pengumpulan data dilakukan terhadap sumber jejak karbon, baik yang langsung (sumber primer) maupun tidak langsung (sumber sekunder). Jenis dan jumlah bahan bakar yang digunakan, peralatan elektronik yang digunakan untuk mengetahui konsumsi listrik, penggunaan kertas, dan penggunaan gas LPG merupakan sumber langsung emisi karbon (sumber primer). Sedangkan data terkait aktivitas transportasi dalam bentuk jenis transportasi, jenis bahan bakar dan jumlah konsumsi bahan bakar yang digunakan merupakan sumber sekunder. Oleh karena itu jumlah proporsi sampel dosen, mahasiswa, dan staf dari seluruh populasi yang berada di Kampus FST Unja dengan penarikan sampel acak berstrata (persamaan 1) secara proporsional adalah sebagai berikut. 
Tabel 1. Jjumlah sampel dosen, staf, dan mahasiswa Fakultas Sains dan Teknologi Universitas Jambi

\begin{tabular}{|c|c|c|c|c|c|c|}
\hline \multirow[t]{2}{*}{ Program Studi } & \multicolumn{2}{|c|}{ Mahasiswa } & \multicolumn{2}{|c|}{ Dosen } & \multicolumn{2}{|c|}{ Staf } \\
\hline & Populasi & Sampel & Populasi & Sampel & Populasi & Sampel \\
\hline Kimia & 191 & 11 & 40 & 10 & 32 & 15 \\
\hline Kimia Industri & 70 & 4 & & & & \\
\hline Fisika & 141 & 8 & & & & \\
\hline Biologi & 145 & 8 & & & & \\
\hline Matematika & 152 & 9 & & & & \\
\hline Analisis Kimia & 96 & 6 & & & & \\
\hline Teknik Pertambangan & 177 & 10 & 16 & 4 & & \\
\hline Teknik Geofisika & 177 & 10 & & & & \\
\hline Teknik Geologi & 151 & 9 & & & & \\
\hline Farmasi & 198 & 11 & 8 & 2 & & \\
\hline Sistem Informasi & 159 & 9 & 10 & 3 & & \\
\hline Total & 1657 & 95 & 74 & 19 & 32 & 15 \\
\hline Total Populasi & & & 17 & & & \\
\hline Total Sampel & & & 12 & & & \\
\hline
\end{tabular}

\subsection{Perhitungan Jejak Karbon}

Jejak karbon merupakan suatu ukuran jumlah total dari hasil emisi $\mathrm{CO}_{2}$ secara langsung (primer) dan secara tidak langsung (sekunder) yang bersumber dari aktivitas manusia. Sumber-sumber emisi $\mathrm{CO}_{2}$ primer dan sekunder tersebut dihitung dengan persamaan pendugaan emisi Gas Rumah Kaca yang secara umum dapat ditulis dalam bentuk persamaan sederhana sebagai berikut.

$$
\text { Emisi }=A D \times F E
$$

Keterangan:

Emisi $=$ Emisi gas $\mathrm{CO}_{2}$ (satuan berat $\mathrm{CO}_{2}$ - equivalent)

$\mathrm{AD}=$ Data aktivitas manusia menghasilkan emisi GRK $\mathrm{FE}=$ Faktor emisi tiap aktivitas

Dalam perhitungan, sumber-sumber primer dan sekunder yang beragam perlu dikategorikan dan dikelompokkan. Salah satu klasifikasi yang sudah dilakukan adalah dari Greenhouse Gases Protocol (GHG Protocol), yang membagi emisi gas rumah kaca ke dalam tiga ruang lingkup (Sprangers, 2011). Ruang Lingkup 1 berupa emisi langsung dari sumber yang dimiliki (dikendalikan) oleh organisasi sendiri seperti pemakaian bahan bakar kendaraan operasional fakultas dan pemakaian LPG. Sedangkan ruang Lingkup 2 merupakan emisi tidak langsung meliputi pemakaian listrik oleh organisasi dan ruang lingkup 3 adalah emisi lainnya baik langsung maupun tidak langsung yang tidak dapat dikontrol oleh perusahaan/organisasi. Selain itu juga dalam ruang lingkup 3 pun dapat berasal dari konsekuensi adanya aktivitas perusahaan/organisasi, seperti pemakaian kertas oleh mahasiswa, pemakaian bahan bakar dari kendaraan mahasiswa, dosen dan staf. Secara lebih detail penentuan pembagian sumber-sumber jejak karbon ke tiap lingkup dan perhitungannya dijelaskan sebagai berikut.

\section{a. Lingkup 1}

Dalam penelitian ini, lingkup satu yang dimaksud adalah dari aktivitas kendaraan operasional, yaitu banyaknya bahan bakar yang dikonsumsi kendaraan operasional pihak FST Unja selama satu tahun. Perhitungannya menggunakan persamaan sebagai berikut.

$$
\text { Emisi }=\text { Konsumsi }_{B B M} x N K_{B B M} x F E
$$

Keterangan:

$$
\begin{array}{ll}
\text { Emisi } & =\text { Emisi as } \mathrm{CO}_{2} \text { (satuan berat } \mathrm{CO}_{2}-\text { eq) } \\
\text { Kons. } \quad B B M & =\text { Konsumsi BBM kendaraan operasional (Liter) } \\
\text { FE } & =\text { Faktor emisi tiap aktivitas }\left(\mathrm{kg} . \mathrm{CO}_{2}-\right.\text { eq/Vol.BB) } \\
\text { NK } & =\text { Nilai Kalor }
\end{array}
$$

Selain itu pemakaian LPG dari aktivitas kantin di FST Unja juga termasuk dalam lingkup satu. Data penggunaan LPG didapatkan melalui kuesioner yang dibagikan kepada seluruh pedagang di kantin FST Unja. Selanjutnya perhitungan jejak karbon aktivitas penggunaan LPG dilakukan dengan persamaan berikut.

Emisi $=$ Konsumsi $_{L P G} \times N_{L P G} \times F E_{(L P G)}$

\section{Keterangan:}

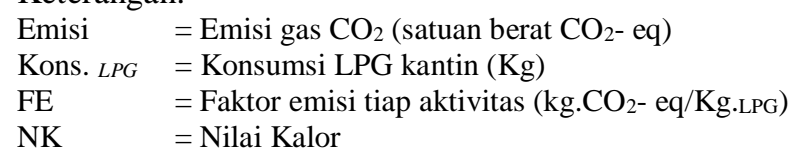

\section{b. Lingkup 2}

Lingkup dua dalam perhitungan jejak karbon yaitu bersumber dari aktivitas pembelanjaan listrik fakultas. Data pemakaian listrik FST Unja dinyatakan dalam satuan $\mathrm{kWh} /$ bulan selama tahun 2018. Untuk mengetahui jumlah jejak karbon dari aktivitas pembelanjaan listrik selanjutnya dimasukkan kedalam Persamaan sebagai berikut.

Emisi $=F E_{C O 2} x$ Konsumsi Listrik

Keterangan :

Emisi

$\mathrm{FE}=$ Faktor emisi $\left(\mathrm{kg} . \mathrm{CO}_{2}-\mathrm{eq} / \mathrm{kWh}\right)$

Konsumsi Listrik = Listrik yang digunakan $(\mathrm{kWh})$

\section{c. Lingkup 3}

Aktivitas yang termasuk kedalam lingkup tiga meliputi aktivitas transportasi oleh dosen, staf, dan mahasiswa ke dan dari kampus FST Unja. Selain itu jejak karbon lingkup tiga berasal dari penggunaan kertas oleh 
mahasiswa, dosen, staf, dan operasional FST Unja. Perhitungan jejak karbon dari aktivitas transportasi dilakukan menggunakan Persamaan 3. Perhitungan jejak karbon dari pemakaian kertas dinyatakan dalam satuan kg/bulan, dengan menggunakan Persamaan sebagai berikut.

Emisi = FE $x$ Pemakaian kertas

Keterangan

Emisi

$\mathrm{FE} \quad=$ Faktor emisi $\left(\mathrm{kg} \cdot \mathrm{CO}_{2}-\mathrm{eq} / \mathrm{Kg}\right.$ kertas)

Pemakaian Kertas $=$ Kertas yang digunakan $(\mathrm{Kg})$

\section{Hasil dan Pembahasan}

Jejak Karbon dan Sumbernya di Fakultas Sains dan Teknologi Universitas Jambi sebagai berikut.

\subsection{Lingkup 1}

Jejak karbon lingkup satu memuat penggunaan bahan bakar kendaraan operasional yang dimiliki oleh FST Unja dan penggunaan LPG di kantin FST Unja. Dalam waktu satu tahun, konsumsi bahan bakar operasional yang digunakan oleh FST Unja sebesar 2.718,89 Liter. Jejak karbon total dari aktivitas transportasi kendaraan operasional FST Unja berupa mobil dinas pada tahun 2018 sebesar 6,218 ton. $\mathrm{CO}_{2}$-eq.

Penggunaan LPG dari kegiatan kampus bersumber dari aktivitas kantin FST Unja selama tahun 2018 sebesar 1998 Kilogram, dengan jejak karbon yang dihasilkan yaitu sebesar 5,96 ton. $\mathrm{CO}_{2}$-eq. Jejak karbon scope 1 dari aktivitas penggunaan BBM Operasional dan LPG Kantin dapat dilihat pada Gambar 3, dari Gambar 3 dapat diketahui bahwa total jejak karbon dari scope 1 sebesar 12,18 ton. $\mathrm{CO}_{2}$-eq.

\subsection{Lingkup 2}

Pelayanan listrik di kampus pinang masak Universitas Jambi memuat kegiatan perkuliahan, administrasi kampus, dan sarana publik. Total penggunaan listrik kampus pinang masak Universitas Jambi untuk tahun 2018 sebesar $1.899 .485 \mathrm{kWh}$. Dari total penggunaan listrik tersebut, pada saat libur perkuliahan yaitu pada Bulan Januari, Juni, Juli, dan Agustus cenderung merupakan saat pemakaian listrik terendah. Sedangkan pada bulan Februari hingga Mei, dan Bulan September hingga Desember pemakaian listrik terus meningkat karena pada masa tersebut aktivitas perkuliahan, akademik, tata usaha, dan laboratorium berjalan, dimana pemakaian terbesar terjadi pada bulan Mei dan November. Hal tersebut disebabkan karena merupakan puncak dari kegiatan perkuliahan, dimana aktivitas perkuliahan berjalan secara optimal serta terdapat kegiatan ujian akhir semester perkuliahan yang tentunya akan berpengaruh terhadap peningkatan pemakaian listrik yang digunakan.

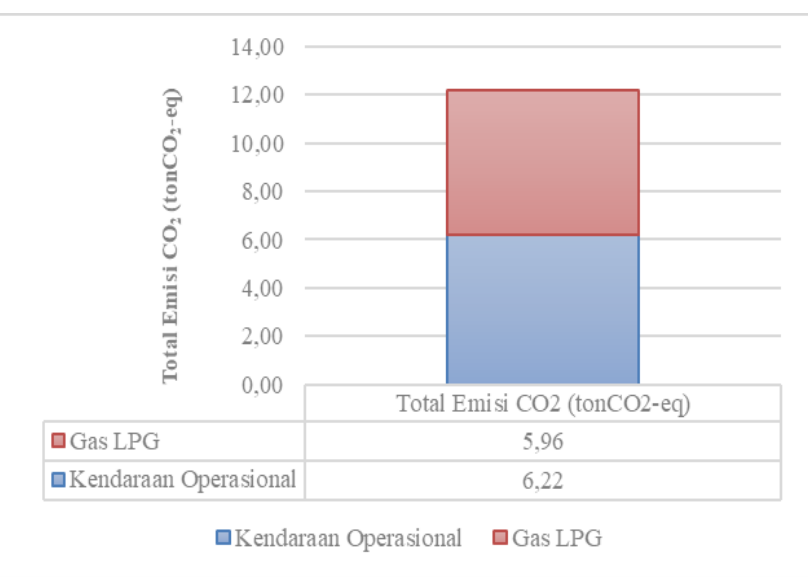

Gambar 3. Total jejak karbon lingkup 1

Gambar di atas merupakan pemakaian listrik untuk keseluruhan kegiatan yang berada di kampus pinang masak Unja. Selanjutnya untuk mengetahui hanya jumlah pemakaian listrik di Fakultas Sains dan Teknologi (FST) saja maka dilakukan perhitungan perbandingan antara luas terbangun FST dengan luas terbangun seluruh kampus pinang masak Unja. Hal ini seperti yang dilakukan oleh Sagala (2016), yang melakukan perbandingan antara luasan terbangun kampus FT Unnes dengan luas terbangun keseluruhan di Universitas Negeri Semarang untuk mengetahui penggunaan listrik di FT Unnes.

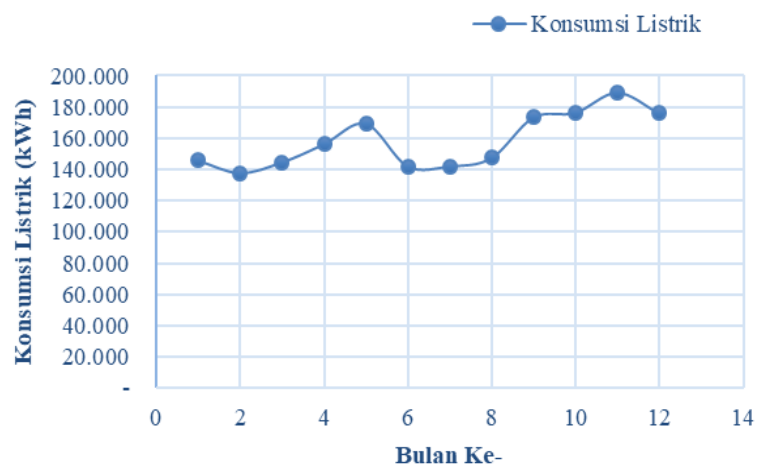

Gambar 4. Pemakaian listrik kampus pinang masak Universitas Jambi

Dengan luas terbangun kampus FST Unja yang sebesar $6,8 \%$ dari $46.421 \mathrm{~m}^{2}$ keseluruhan luas terbangun di kampus pinang masak, didapatkan besar pemakaian listrik FST Unja dari hasil perhitungan perbandingan luas terbangun adalah sebesar $129.504 \mathrm{kWh}$ pada tahun 2018 . Sedangkan nilai jejak karbon dari pembelanjaan listrik FST Unja dapat dilihat pada tabel sebagai berikut.

Tabel 2. Hasil perhitungan jejak karbon lingkup 2

\begin{tabular}{rlrrr}
\hline No & \multicolumn{1}{c}{ Kategori Ruangan } & Total Luas (m2) & $\mathrm{kWh} /$ Tahun & $\mathrm{Emisi}^{\mathrm{CO}_{2}(\text { ton.CO }} \mathrm{CO}_{2}$-eq) \\
\hline 1 & Ruang Kuliah & 459 & 22003 & 17,0 \\
2 & Laboratorium & 1399,5 & 67089 & 52,0 \\
3 & Kantor, Dekanat, TU, dan Jurusan & 645 & 30920 & 23,9
\end{tabular}


4 Fasilitas Umum

TOTAL
198

2701,5
9492

129504
7,4

100,3
Jejak karbon total dari aktivitas pembelanjaan listrik FST pada tahun 2018 sebesar 100,3 ton. $\mathrm{CO}_{2}$-eq. Berdasarkan Gambar 5 dapat diketahui bahwa penghasil jejak karbon dari pembelanjaan listrik FST Unja terbesar dari aktivitas penggunaan ruang laboratorium, yaitu sebesar 52,0 ton. $\mathrm{CO}_{2}$-eq dimana keseluruhan laboratorium yang ada di FST Unja seluas 1399,5 $\mathrm{m}^{2}$.

Jika dilihat dari fungsi ruangan, laboratorium FST Unja memiliki fungsi dan kegiatan yang banyak membutuhkan energi listrik, seperti penggunaan alat-alat laboratorium, pencahayaan, pendingin ruangan, dan penyimpanan sampel uji. Dari perhitungan jejak karbon pada lingkup dua penggunaan listrik Kampus FST Unja, jika hanya sebatas dilihat dari variabel luas ruangan dan hubungannya dengan emisi $\mathrm{CO}_{2}$ yang dihasilkan (Gambar 5) dapat diketahui bahwa semakin luas ruangan akan menghasilkan emisi $\mathrm{CO}_{2}$ yang semakin besar.

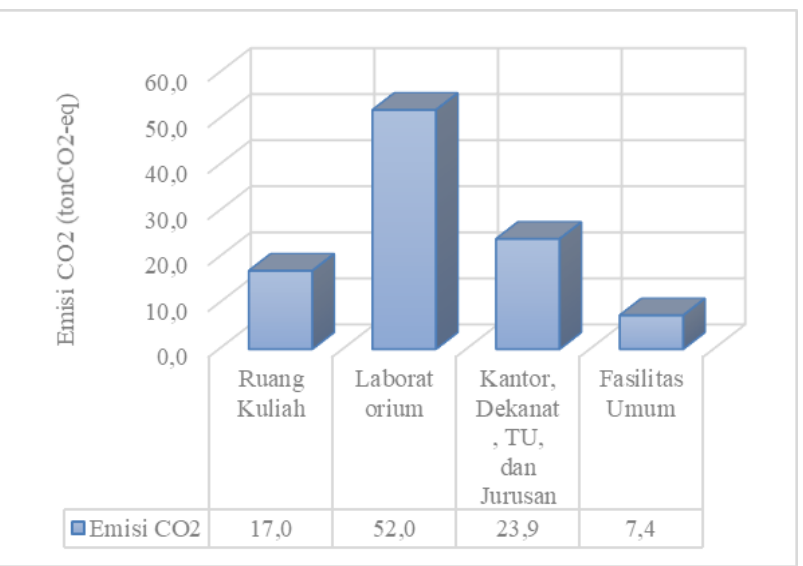

Gambar 5. Jejak karbon scope 2

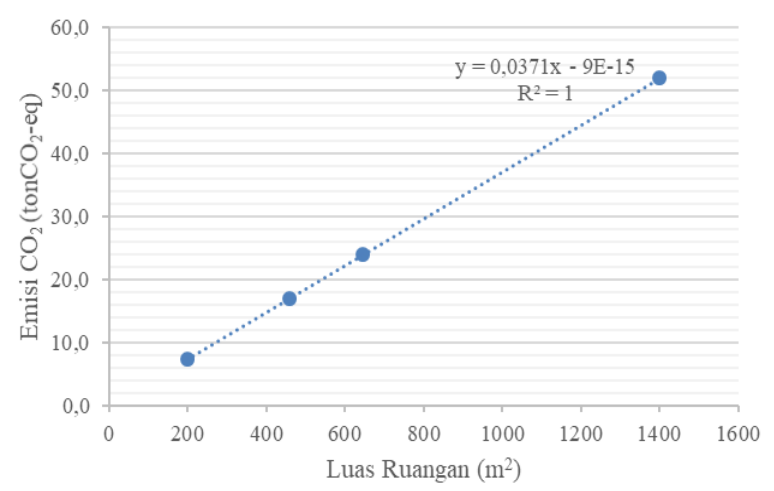

Gambar 6. Hubungan luas ruangan dengan emisi $\mathrm{CO}_{2}$

\subsection{Lingkup 3}

Jejak karbon scope 3 meliputi aktivitas transportasi berupa konsumsi bahan bakar dan penggunaan kertas oleh dosen, staf, dan mahasiswa.

\section{a. Transportasi Dosen, Staf, dan Mahasiswa}

Jejak karbon dari aktivitas transportasi diketahui berdasarkan pemilihan moda transportasi, jenis bahan bakar, dan jarak tempuh. Jumlah penumpang dan frekuensi melakukan perjalanan ke kampus juga mempengaruhi besar emisi jejak karbon. Pada Gambar 7 menunjukkan bahwa moda transportasi yang paling dominan digunakan oleh dosen, staf, dan mahasiswa yaitu moda transportasi sepeda motor. Sebanyak 100\% staf menggunakan moda transportasi sepeda motor, selanjutnya mahasiswa sebanyak $87,4 \%$ dan dosen sebanyak 63,2\%. Pemilihan moda transportasi umum sangat sedikit digunakan, hanya sebesar 3,2\% mahasiswa yang memilih menggunakan moda transportasi umum dan $6,3 \%$ mahasiswa yang memilih untuk berjalan kaki.

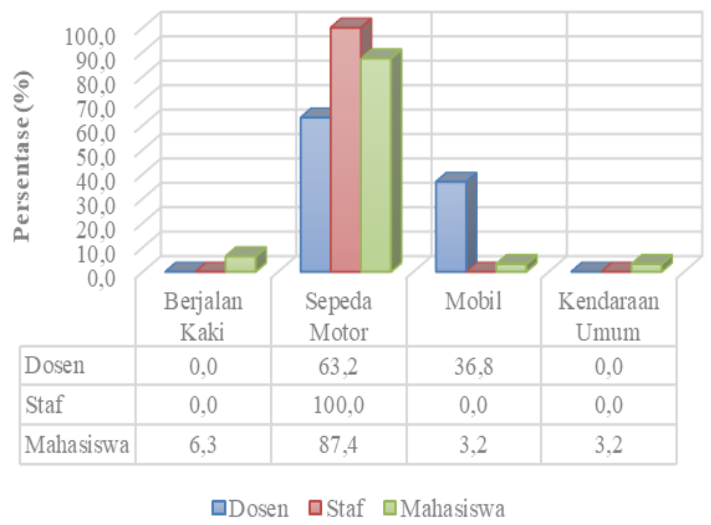

Gambar 7. Persentase Moda Transportasi Dosen, Staf, dan Mahasiswa

Frekuensi perjalanan dosen, staf, dan mahasiswa ke kampus FST Unja juga turut mempengaruhi besarnya emisi jejak karbon yang dikeluarkan (Gambar 8). Untuk frekuensi perjalanan ke kampus FST Unja oleh dosen dan staf cenderung tidak berbeda pada masa aktif perkuliahan dan masa libur perkuliahan setiap minggunya. Akan tetapi untuk mahasiswa frekuensi melakukan perjalanan ke kampus FST Unja sangat berbeda, yaitu sebesar 5,53 kali setiap minggunya saat aktif perkuliahan dan 1,59 kali saat libur perkuliahan.

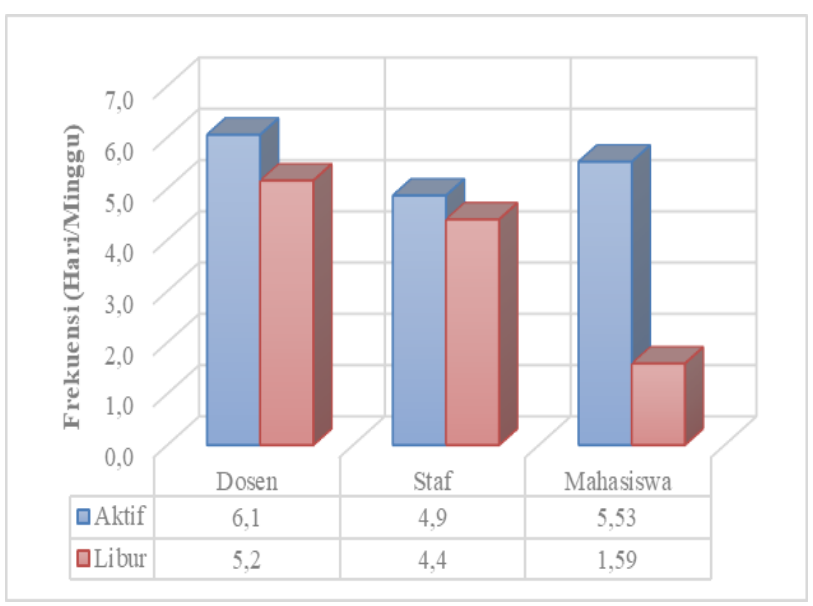

Gambar 8. Frekuensi perjalanan ke kampus

Nilai jejak karbon aktivitas transportasi dosen, staf, dan mahasiswa didapatkan dengan mencari rata-rata emisi $\mathrm{CO}_{2}$ sebagai jejak karbon dari masing-masing kendaraan kemudian dikalikan dengan persentase pemilihan moda 
transportasi dosen, staf, dan mahasiswa (Sagala, 2016). Jejak karbon dari aktivitas transportasi dapat dilihat pada Gambar 9. Total keseluruhan jejak karbon dari aktivitas transportasi oleh dosen, staf, dan mahasiswa untuk tahun 2018 yaitu sebesar 427,38 ton. $\mathrm{CO}_{2}$-eq/tahun. Dimana emisi jejak karbon terbesar dihasilkan oleh mahasiswa yaitu sebesar 353,51 ton $\mathrm{CO}_{2}$-eq, hal ini dikarenakan faktor populasi mahasiswa yang cukup besar.

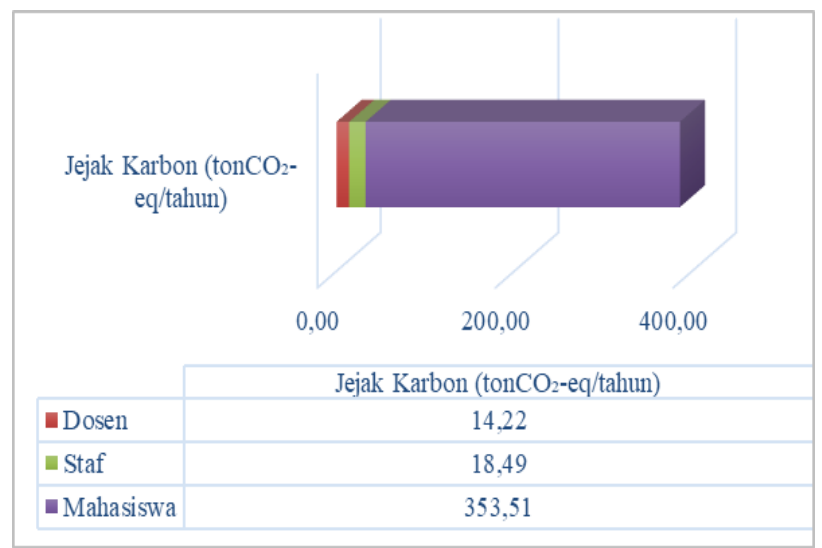

Gambar 9. Jejak karbon aktivitas transportasi

\section{b. Penggunaan Kertas}

Jejak karbon aktivitas penggunaan kertas oleh dosen, staf, dan mahasiswa, perlunya mengetahui persentase pemilihan kertas oleh masing-masing responden dari masing-masing jenis kertas A4 $70 \mathrm{gsm}$ dan A4 80 gsm dikalikan dengan rata-rata penggunaan kertas oleh masing-masing responden untuk mengetahui proyeksi pemakaian kertas (rim) yang digunakan.

Gambar 10 menunjukkan total emisi $\mathrm{CO}_{2}$ sebagai emisi jejak karbon dari aktivitas penggunaan kertas, dimana total emisi jejak karbon sebesar 16,25 ton. $\mathrm{CO}_{2}$-eq. Emisi terbesar dihasilkan dari aktivitas penggunaan kertas oleh mahasiswa, yaitu sebesar 14,61 ton. $\mathrm{CO}_{2}$-eq. Untuk aktivitas penggunaan kertas oleh staf menghasilkan emisi sebesar 0,821 ton. $\mathrm{CO}_{2}$-eq. Sedangkan emisi jejak karbon terkecil dihasilkan dari penggunaan kertas oleh dosen, yaitu sebesar 0,816 ton. $\mathrm{CO}_{2}$-eq.

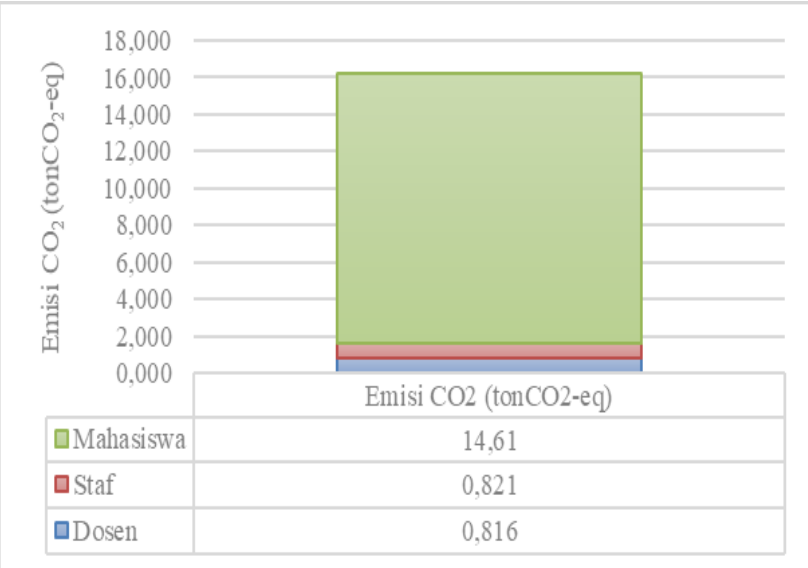

Gambar 10. Jejak karbon aktivitas penggunaan kertas

\subsection{Total Jejak Karbon}

Total jejak karbon dari aktivitas kampus di FST Unja merupakan jumlah keseluruhan emisi $\mathrm{CO}_{2}$ sebagai jejak karbon dari scope 1, scope 2, dan scope 3. Jejak karbon dari scope 1 sebesar 12,18 ton. $\mathrm{CO}_{2}$-eq atau sebesar 2,19\% dari keseluruhan emisi jejak karbon dimana pada scope 1 memuat sektor konsumsi BBM Operasional dan Konsumsi LPG Kantin Kampus. Jejak karbon scope 2 aktivitas pemakaian listrik sebesar 100,29 ton. $\mathrm{CO}_{2}$-eq dengan persentase $18,03 \%$. Untuk jejak karbon scope 3 berasal dua sektor, yaitu dari aktivitas transportasi dosen, staf, dan mahasiswa, dan dari aktivitas penggunaan kertas dengan jumlah emisi sebesar 443,64 ton. $\mathrm{CO}_{2}$-eq atau 79,78\%. Total jejak karbon dari aktivitas kampus di Fakultas Sains dan Teknologi Universitas Jambi dapat dilihat dalam Tabel 3 dan Gambar 11.

Gambar 11 dapat diketahui bahwa jejak karbon dari aktivitas kampus di FST Unja terbesar dihasilkan oleh scope 3, yaitu aktivitas transportasi dosen, staf dan mahasiswa dan aktivitas pemakaian kertas dengan total emisi sebesar 443,64 ton. $\mathrm{CO}_{2}$-eq. Selanjutnya emisi yang cukup besar juga dihasilkan oleh aktivitas pemakaian listrik pada lingkup 2 dengan nilai emisi sebesar 100,29 ton. $\mathrm{CO}_{2}$-eq. Lingkup 1 dari aktivitas konsumsi BBM operasional dan konsumsi LPG menyumbang emisi sebesar 6,22 ton. $\mathrm{CO}_{2}$-eq.

Tabel 3. Total jejak karbon aktivitas kampus

\begin{tabular}{clcccc}
\hline Ruang Lingkup & \multicolumn{2}{c}{ Sektor } & \multicolumn{2}{c}{ Persentase (\%) } & \multicolumn{2}{c}{ Emisi CO (ton.CO $\mathrm{CO}_{2}$-eq) } \\
\hline Scope 1 & Konsumsi BBM Operasional & 1,12 & 2,19 & 6,22 & 12,18 \\
& Konsumsi LPG & 1,07 & & 5,96 & \\
Scope 2 & Pemakaian Listrik & 18,03 & 18,03 & 100,29 & 100,29 \\
Scope 3 & Transportasi Dosen, Staf, dan Mahasiswa & 76,85 & 79,78 & 427,38 & 443,64 \\
& Penggunaan Kertas & 2,92 & & 16,25 & 556,10
\end{tabular}

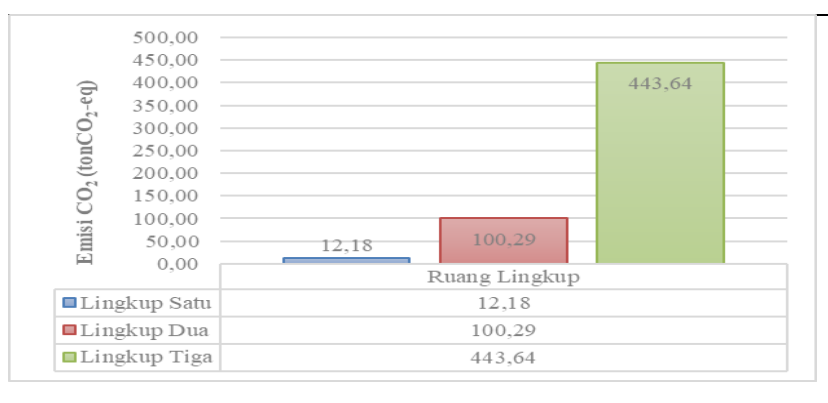

\section{Gambar 11. Total jejak karbon aktivitas kampus}

Penelitian jejak karbon di kampus Fakultas Ilmu Budaya Universitas Diponegoro juga menunjukkan bahwa jejak karbon terbesar dihasilkan dari lingkup 3 dari aktivitas Kendaraan mahasiswa, dosen, dan tenaga kependidikan dengan jejak karbon sebesar 1.125 ton. $\mathrm{CO}_{2-}$ eq (Azizah dkk, 2017). UCSI University Malaysia yang juga melakukan evaluasi terhadap jejak karbon untuk 
menilai kemajuan dan keberhasilan diterapkannya Green Campus Initiative (GCI) di UCSI University Malaysia dengan hasil emisi gas rumah kaca (GRK) terbesar dari penggunaan energi listrik dengan jumlah rata-rata penggunaan sebesar $280.805 \mathrm{kWh}$ tiap bulannya dengan emisi GRK sebesar 150 ton. $\mathrm{CO}_{2}$-eq/bulan, sedangkan penggunaan bahan bakar kendaraan operasional sebesar 3132,192 liter/bulan dengan emisi GRK sebesar 112,7 ton. $\mathrm{CO}_{2}$-eq/bulan (Hooi dkk, 2011).

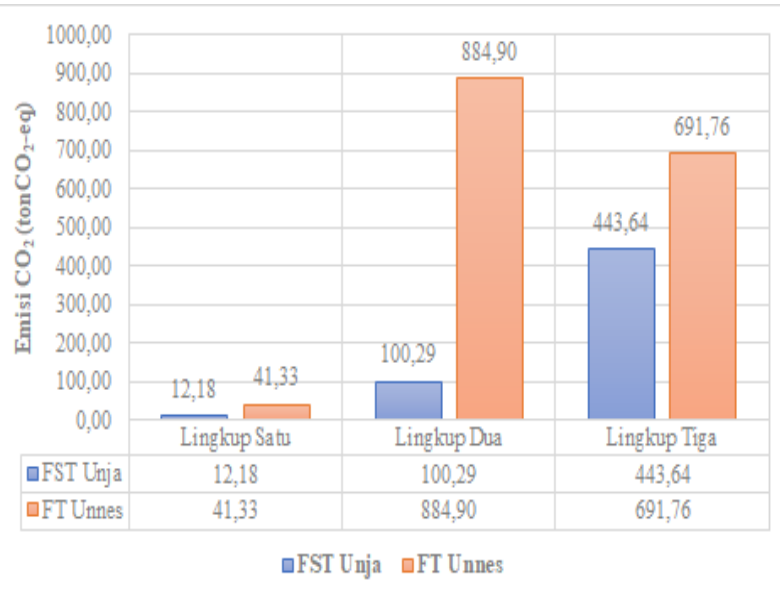

Gambar 12. Perbandingan jejak karbon di universitas

Perhitungan jejak karbon di FST Unja dibandingkan dengan Fakultas Teknik Universitas Negeri Semarang (Unnes) yang juga melakukan perhitungan jejak karbon (Sagala, 2017). Gambar X menunjukkan jejak karbon tertinggi dari FT Unnes dihasilkan dari aktivitas penggunaan listrik di lingkup dua, sedangkan dari FST Unja jejak karbon tertinggi dihasilkan dari aktivitas transportasi kendaraan pribadi dosen, staf, dan mahasiswa pada lingkup tiga. Total jejak karbon dari ketiga lingkup di FT Unnes lebih besar dibandingkan dengan FST Unja, yaitu 1618,00 ton. $\mathrm{CO}_{2}$-eq sedangkan total jejak karbon FST Unja 556,10 ton. $\mathrm{CO}_{2}$-eq

\section{Kesimpulan}

Berdasarkan penelitian ini, dapat disimpulkan sebagai berikut:

1. Jejak karbon dari aktivitas di Fakultas Sains dan Teknologi Universitas Jambi pada tahun 2018 dihitung berdasarkan tiga ruang lingkup:

a. Lingkup satu: aktivitas pemakaian BBM operasional menghasilkan 6,218 ton. $\mathrm{CO}_{2}$-eq/tahun dan aktivitas penggunaan LPG kantin menghasilkan 5,96 ton. $\mathrm{CO}_{2}$-eq/tahun.

b. Lingkup dua: aktivitas pembelanjaan listrik menghasilkan 100,3 ton. $\mathrm{CO}_{2}$-eq.

c. Lingkup tiga: aktivitas transportasi dosen, staf, dan mahasiswa menghasilkan 427,38 ton. $\mathrm{CO}_{2}$-eq/tahun dan aktivitas penggunaan kertas menghasilkan 16,25 ton. $\mathrm{CO}_{2}$-eq/tahun.

2. Total jejak karbon yang dihasilkan dari aktivitas Kampus Fakultas Sains dan Teknologi Universitas Jambi pada tahun 2018 sebesar 556,10 ton. $\mathrm{CO}_{2}$-eq. Nilai jejak karbon terbesar dihasilkan dari aktivitas transportasi oleh mahasiswa, staf, dan dosen untuk melakukan perjalanan menuju dan dari kampus.

\section{Daftar Pustaka}

Azizah, TN. 2016. Kajian Jejak Karbon Dan Pemetaannya Dari Aktivitas Kampus Di Fakultas Ilmu Budaya Universitas Diponegoro. Jurnal Teknik Lingkungan, 6(13).

Boer, R. Dkk. 2012. Pedoman Penyelenggaraan Inventarisasi Gas Rumah Kaca Nasional. Kementerian Lingkungan Hidup, Republik Indonesia Jakarta.

Dahlan, EN. 2008. Jumlah Emisi Gas CO2 dan Pemilihan Jenis Tanaman Berdaya Rosot Sangat Tinggi: Studi Kasus Di Kota Bogor. Media Konservasi, 13(2) : 85 89.

Effendi, JS. Dkk. 2015. Design and Implementation of Power Supply For Pc With Power Saving on Battery System. e-Proceeding of Applied Science, 1 (2) : 1283-1298.

Badan Perencanaan Pembangunan Nasional, Republik Indonesia. 2013. Pedoman Teknis Penghitungan Baseline Emisi dan Serapan Gas Rumah Kaca Sektor Berbasis Lahan: Buku I Landasan Ilmiah.

Gupta, PK \& Singh, G. 2012. Minimizing Power Consumption by Personal Computers: A Technical Survey. Information Technology and Computer Science, (10) : 57-66.

Hooi, KK. 2011. Sustainable Education: An Assessment of Carbon Footprint at UCSI University and Proposed Green Campus Initiative Framework. IPEDR, Vol. 12. IACSIT Press, Singapura.

Pedoman Penghitungan dan Pelaporan Inventarisasi Gas Rumah Kaca Bidang Energi - Sub Bidang Ketenagalistrikan. Direktorat Jenderal Ketenagalistrikan Kementerian ESDM.

Peraturan Menteri Lingkungan Hidup dan Kehutanan Republik Indonesia Nomor P. 73 Tahun 2017 tentang Pedoman Penyelenggaraan dan Pelaporan Inventarisasi Gas Rumah Kaca Nasional.

Peraturan Menteri Lingkungan Hidup Republik Indonesia Nomor 15 Tahun 2013 tentang Pengukuran, Pelaporan, dan Verifikasi Aksi Mitigasi Perubahan Iklim.

Peraturan Menteri Negara Lingkungan Hidup Nomor 12 Tahun 2010 tentang Pelaksanaan Pengendalian Pencemaran Udara di Daerah.

Peraturan Presiden Republik Indonesia Nomor 61 Tahun 2011 tentang Rencana Aksi Nasional Penurunan Gas Rumah Kaca.

Peraturan Presiden Republik Indonesia Nomor 71 Tahun 2011 tentang Penyelenggaraan Inventarisasi Gas Rumah Kaca Nasional.

Pratiwi, WAK \& Hermana, J. 2013. Analisis Pengurangan Emisi CO2 Melalui Manajemen Penggunaan Listrik dan Ketersediaan Ruang Terbuka Hijau di Gedung Perkantoran Pemerintah Kota Surabaya. Jurnal Teknik Pomits. 2 (3): 2301-9271.

Prihatmaji, YP dkk. 2016. Analisis Carbon Footprint Gedung Perpustakaan Pusat, Rektorat, dan Lab. 
MIPA UII Berbasis Vegetasi Eksisting Sebagai Pereduksi Emisi Gas Rumah Kaca. Asian Journal of Innovation and Entrepreneurship (AJIE), 01 (02) : $148-155$.

Putri M, DA. Dkk. 2017. Kajian Jejak Karbon Dari Aktivitas Kampus Fakultas Ekonomika Dan Bisnis Universitas Diponegoro. Jurnal Teknik Lingkungan, $6(1)$.

Sagala, S. 2017. Kajian Jejak Karbon Dari Aktivitas Kampus Di Fakultas Teknik Universitas Negeri Semarang. Jurnal Teknik Lingkungan, 6 (1).

Sprangers, S. 2011. Calculating the Carbon Footprint of Universities. Erasmus Universiteit Rotterdam.

Sukoso, P \& Wardani, WS. 2011. Analisis Konsumsi Energi Listrik Pada Berbagai Jenis Lampu Dan Komputer Untuk Acuan Dalam Audit Energi. Politeknologi, 10 (3).

The National Academies of SEM. 2011. America's Climate Choices. The National Academies Press. Washington, DC.

The National Academies of SEM. 2016. Attribution of Extreme Weather Events in the Context of Climate Change. The National Academies Press. Washington, DC.

Wahid, A. Dkk. 2014. Analisis Kapasitas Dan Kebutuhan Daya Listrik untuk Menghemat Penggunaan Energi Listrik di Fakultas Teknik Universitas Tanjungpura. Pontianak. Universitas Tanjungpura.

Wiedmann, T. dan Minx, J. 2007. A Definition of 'Carbon Footprint'. United Kingdom. ISA UK Research \& Consulting.

Wulandari, MT. 2013. Kajian Emisi CO2 Berdasarkan Penggunaan Energi Rumah Tangga Sebagai Penyebab Pemanasan Global (Studi Kasus Perumahan Sebantengan, Gedang Asri, Susukan RW 07 Kab. Semarang). Prosiding Seminar Nasional Pengelolaan Sumberdaya Alam dan Lingkungan 2013, 1 (2) : 434-440. 